\title{
Congenital and late onset vertebral fusions in long necked plesiosaurs: The first report of spondylosis deformans in Sauropterygians
}

\author{
Judyth Sassoon
}

\begin{abstract}
Fossilised osseous pathologies can provide useful information about the lifestyles and habits of extinct vertebrates. The Plesiosauria were a diverse Mesozoic marine reptile clade with a unique body plan, exhibiting variations in head and neck morphology. Palaeopathologies are generally uncommon in plesiosaurs but in this study, pathological spinal fusions were identified in the cervical vertebrae of four long-necked, plesiosauromorph specimens from different stratigraphic horizons. The fusions were of two types: a congenital condition (block vertebrae) and a late onset condition, strongly resembling spondylosis deformans. Spondylosis deformans is a non-inflammatory degeneration of intervertebral discs, characterised by the formation of bony projections across the disc space. The condition is commonly identified in extant, domestic animals and humans, but this is the first report of spondylosis deformans in the Plesiosauria. In domestic animals, especially older dogs, spondylosis causes stiffness and pain. The significance of spinal fusions as causes of neck stiffness in long-necked plesiosaurs is discussed and their debilitating potential considered.
\end{abstract}

Judyth Sassoon. School of Earth Sciences, University of Bristol, Queen's Road, Bristol, BS8 1RJ, UK. js7892@bristol.ac.uk

Keywords: Plesiosauria; palaeopathologies; spinal fusions; Mesozoic marine reptiles; spondylosis deformans; cervical vertebrae

Submission: 8 August 2018 Acceptance: 11 December 2018

\section{INTRODUCTION}

Spinal fusions are bone disorders that appear in both extant and extinct vertebrates and can have a variety of aetiologies, which are not always easy to diagnose (Rogers et al., 1985; Rothschild and
Berman, 1991; Martin and Bell, 1995; Rothschild, 1997; Littleton, 1999; Rothschild and Martin, 2006; Rothschild et al., 2012). Vertebral fusions can be congenital and present from birth or develop later in life (Erdil et al., 2013). Late onset vertebral

Sassoon, Judyth. 2019. Congenital and late onset vertebral fusions in long necked plesiosaurs: The first report of spondylosis deformans in Sauropterygians. Palaeontologia Electronica 22.1.1A 1-15. https://doi.org/10.26879/913 palaeo-electronica.org/content/2019/2376-spinal-fusions-in-plesiosaurs 
fusions may be associated with bone hyperostosis and include spondylosis deformans, diffuse idiopathic skeletal hyperostosis (DISH) and spondyloarthropathies such as osteoarthritis of the facet joints and ankylosing spondylitis (Reswick, 1985).

The nomenclature of conditions presenting with spinal fusions is often confusing because some terms are used casually, without adhering to precise diagnostic criteria. For example, the term spondylosis deformans has occasionally been used to describe the condition more properly called diffuse idiopathic skeletal hyperostosis or DISH (Kranenburg et al.,2013). Also, confusion arises in the indiscriminate use of the terms "spondylitis," which refers to an inflammatory condition and "spondylosis," a degenerative condition in which there is no inflammation (Chi et al., 2007).

In the fossil record fused vertebrae are found in various mammals (Rothschild and Martin, 2006), fishes (Britz and Johnson, 2005), extant reptiles (Rothschild, 1997) and extinct reptiles, especially non-avian dinosaurs (Blumberg and Sokoloff, 1961; Rothschild and Berman, 1991; Rothschild, 1997; Molnar, 2001; Butler et al., 2013; Farke and O'Connor, 2007). Vertebral fusions have also been reported in Mesozoic marine reptiles, such as mosasaurs from the Cretaceous but have not been discussed to any great extent in another highly successful marine tetrapod clade, the Plesiosauria (Reptilia: Sauropterygia) (Mulder, 2001; Rothschild and Everhart, 2015). This is despite the fact that a spinal fusion was one of the earliest pathologies recorded in plesiosaurs (Mudge, 1878).

Plesiosaurians were globally distributed in the Mesozoic oceans and the longest surviving group of secondarily marine reptiles, spanning over 135 million years from the Uppermost Triassic to the Late Cretaceous (Brown, 1981). The unique, barrel-bodied, four flipper morphology adapted for efficient and active swimming was the iconic body plan of the Plesiosauria. Moreover, plesiosaurians fell into one of two further morphological divisions: long-necked, small-headed plesiosauromorphs or large-headed, short-necked pliosauromorphs (O'Keefe, 2002). These categories evolved independently and repeatedly, and reflect convergences or ecomorphological adaptations, rather than phylogenetic relationships (Benson and Druckenmiller, 2014). From surveys of plesiosaurian specimens in collections from the UK, Germany and the U.S., vertebral fusions appear to have been more common in the long-necked plesiosaurians than pliosauromorphs (personal observation). This paper presents four plesiosauromorph plesiosaurs, showing fusions of cervical vertebrae. The specimens are from different geological horizons, ranging from the Oxford Clay, to Upper Jurassic and Cretaceous. Descriptions of the pathologies are followed by tentative diagnoses and a general discussion of the underlying conditions.

Institutional abbreviations. CAMSM, Sedgwick Museum, Cambridge, UK; GPIT, GeologischPaläontologisches Institut Tübingen, Tübingen, Germany; NMW, National Museum of Wales, Cardiff, UK; UCMP, University of California Museum of Paleontology, Berkeley, California USA.

Other abbreviations. DISH, diffuse idiopathic skeletal hyperostosis.

\section{SYSTEMATIC PALAEONTOLOGY}

Superorder SAUROPTERYGIA (Owen, 1860)

Order PLESIOSAURIA (de Blainville, 1835)

Superfamily PLESIOSAUROIDEA (Gray, 1825)

Family CRYPTOCLIDIDAE (Williston, 1925)

\section{Description}

NMW 19.96.G17 is a juvenile Muraenosaurus sp. (estimated length $<3.5 \mathrm{~m}$ ) from the Oxford Clay Formation (Callovian, Middle Jurassic) of $\mathrm{S}$. England, represented by fragments of parietal, left mandibular ramus, neural spines, propodials, two radii, possible ulna and unidentified epipodials, mesopodials, phalanges. The entire spinal column is preserved, consisting of 90 vertebrae of which 39 are cervicals, three pectorals, 20 dorsals, three sacrals, and 25 caudals. A few small posteriormost caudals may be missing. The total length of the vertebral column is $3.28 \mathrm{~m}$. The specimen can be confidently identified as an older juvenile by its size, humerus shape and morphology of proximal articulating surfaces of propodials and unfused neurocentral arches (Brown, 1981; Kear, 2007; Sachs et al., 2016).

The twelfth and thirteenth cervical vertebrae are completely ankylosed (Figure 1.1-4) and would have behaved as a single element in the spinal column. The block is $3.3 \mathrm{~cm}$ high, measured along the dorso-ventral axis. The total anteroposterior length of the two fused vertebrae is $5 \mathrm{~cm}$. The anterior element is $2.3 \mathrm{~cm}$ long and the posterior $2.7 \mathrm{~cm}$ long (anteroposteriorly). The anteroposterior length of the element immediately preceding the fused block is $4 \mathrm{~cm}$ and that of the element following is $4.2 \mathrm{~cm}$. So the fused block is longer than the expected length of an individual vertebral element at that position, but shorter than the expected length of two unfused consecutive vertebrae. The periosteum has been abraded on the right lateral 

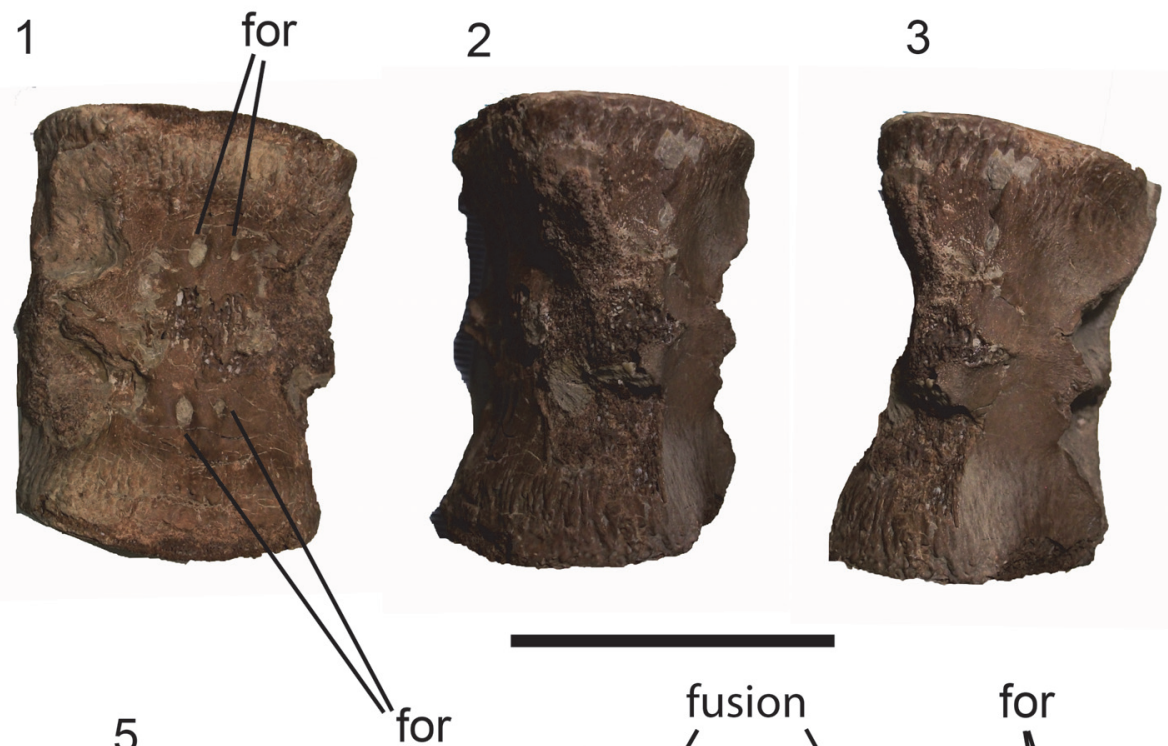

4

5
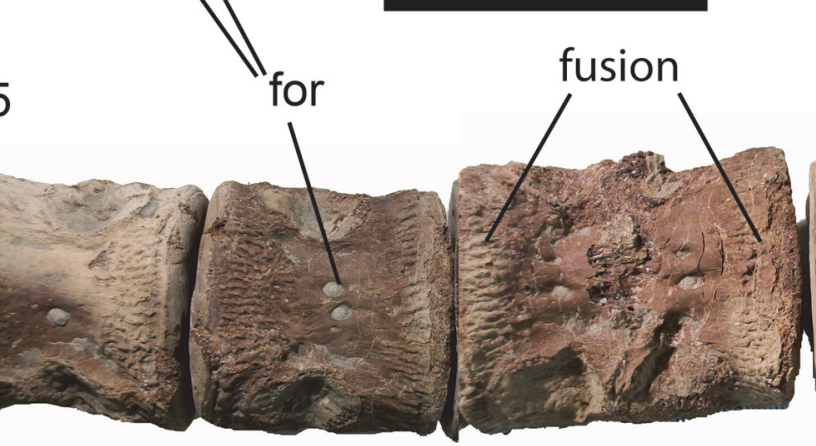

10

11

12

13

14

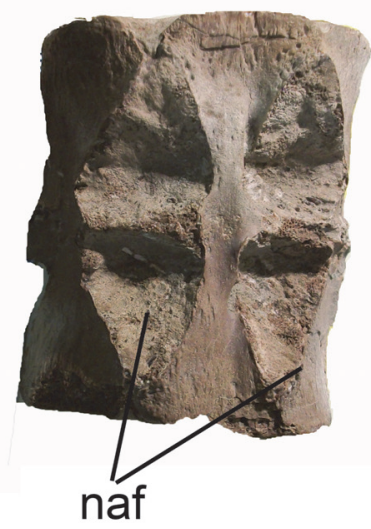

6

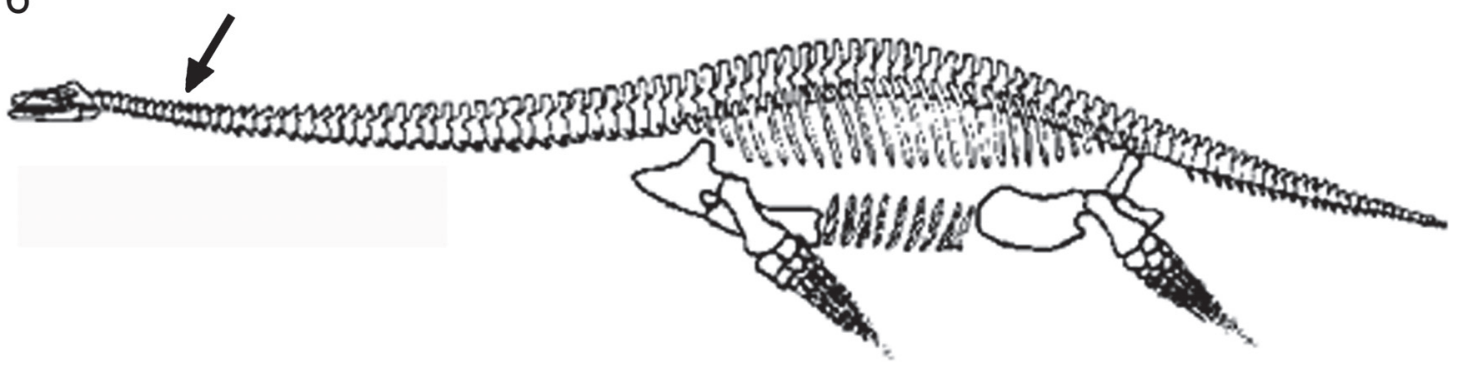

FIGURE 1. Fused cervical vertebrae 12 and 13 in juvenile Muraenosaurus sp. (NWM 19.96.G17) in 1. ventral 2. left lateral 3. right lateral and 4. dorsal view. 5. Ventral view of vertebral series (numbered), showing abnormal position of ventral foramina in vertebrae 10 and 11, and symmetrical positioning in 14, 15. 6. Reconstruction of Muraenosaurus (from Andrews, 1910) showing position of vertebral fusion. Abbreviations: for, foramina subcentralia; naf, neural arch facets. Scale bar equals $4 \mathrm{~cm}$.

side of the fusion assuming the shorter vertebra is more anterior. This may have occurred during preparation. On the left lateral side, the periosteum is continuous with no visible demarcation between elements. The ventral surface is rugose at the line of fusion, but there is no overgrowth, which would be expected with a traumatic injury or spondyloar- thropathy (Rothschild et al., 2002). The cervical rib facets are not well developed.

In the three vertebrae anterior to the fusion, the ventral foramina subcentralia are abnormally displaced in the following way. Whilst in the other cervical vertebrae, the foramina subcentralia are symmetrical about the vertebral median axis, in the 
ninth vertebral element of the series they are underdeveloped and in the tenth and eleventh the foramina are closer together, asymmetrical and, especially in the eleventh element, displaced more posteriorly. In the eleventh vertebral element, the right foramen is displaced further posteriorly than the left (Figure 1.5). The rest of the material from NMW 19.96.G17 is free from visible pathologies.

\section{Subfamily COLYMBOSAURINAE Benson and Bowdler, 2014 \\ Type Genus Colymbosaurus Seeley, 1874}

\section{Description}

Specimen CAMSM J63919. Colymbosaurus megadeirus (Benson and Bowdler, 2014) is an incomplete vertebral series consisting of 36 cervical (excluding atlas-axis complex), four pectoral, 17 dorsal, three sacral and 28 caudal vertebrae. An atlas-axis complex for this specimen was reported by Barrett (1858) but is now missing. There are also broken fragments of dorsal ribs, at least five with healed fractures.

Rounded, anteroventrally projecting, spur-like expansions are present on the ventral surfaces of four cervical vertebrae previously identified as belonging in positions $26-28$ and 31 on the basis of museum notes (Benson and Bowdler, 2014). The expanded spurs project from the anterior surface of the vertebra to touch and cover the posterior surface of the preceding vertebra. However, detailed observations of the pathological vertebrae suggest they are a series with no gaps (museum numbers J63919 v, w, x, aa; estimated positions 26 to 29) (Figure 2.1-3). Benson and Bowdler (2014) also observed that the expansions contacted rugosities on the preceding vertebra, considered to be traumatic exostoses due to the irritation. However, closer observations discovered rugosities on almost every cervical vertebra not only those adjacent to the pathological expansions, so the rugosity seems to be a normal feature in this specimen. Other pathologies found on CAMSM J63919 were rib fractures, which may not be associated with the vertebral pathology.

Superfamily PLESIOSAUROIDEA (Gray, 1825)

\section{Description}

Specimen GPIT.RE.03173 is an unknown plesiosauroid housed in the collections of the Geologisch-Paläontologisches Institut, Tübingen, Germany. It consists of two vertebrae: the terminal cervical and first pectoral of an unknown plesiosauroid, preserved in articulation. There is a large ventral expansion on the posterior face of the cervical vertebra, projecting posteriorly to touch the pectoral vertebra at a facet, possibly formed as a result of irritation by the projecting osseous mass (Figure 2.4-5).

Family ELASMOSAURIDAE (Cope, 1869 sensu Ketchum and Benson, 2010)

Type Genus Callawayasaurus (Carpenter, 1999)

Species Callawayasaurus colombiensis (Welles, 1962)

Type species. UCMP 38349, Callawayasaurus columbensis formerly Alzadasaurus colombiensis described by Welles (1962). Revised under a new generic name Callawayasaurus, by Carpenter (1999, p. 172).

Type locality. Paja Formation (Lower Aptian faunal stage, 125-112 Ma), Leiva Shale, early Cretaceous of Columbia. $120 \mathrm{~km} \mathrm{~N}$ and $60-70 \mathrm{~km}$ Bogota. (Welles, 1962; Goñi and Gasparini, 1983; Carpenter, 1999).

\section{Description}

Specimen UCMP 38349, Callawayasaurus columbensis, has been extensively described by Welles (1962). However, no reference was made to the pathological condition which is clearly present on a few of the cervical vertebrae. Since UCMP 38349 has been described previously, only a brief account of the cervical vertebrae is included, with additional details of the previously undescribed pathology.

Thirty-five vertebrae from the series belonging to UCMP 38349 were studied. They were identified as anterior and medial cervical vertebrae on the basis of size and position in the preserved series. The exact position of these vertebrae in the spinal column has been debated. O'Keefe and Hiller (2006) stated that the cranialmost vertebrae are missing from this specimen. However, Sven Sachs (Sachs, personal commun. 2018) observed that the series was complete. The numbering system used here is as marked on the specimen. Callawayasaurus typically has 56 cervical vertebrae (Carpenter, 1999).

The anterior and medial cervical centra of $\mathrm{Cal}-$ lawayasaurus are longer than high or broad, and broader than high: on average 1.13x longer than high and $1.29 x$ broader than high. The centra are slightly amphicoelous with a thickened rim surrounding the outer region of the articular facet, which is the condition in many elasmosaurid taxa (Sachs and Kear, 2015). Intervertebral discs (soft tissue) were replaced by matrix so the original intervertebral spacing is preserved. Vertebrae are separated by approximately $10-15 \mathrm{~mm}$. Ventrally 
1

2

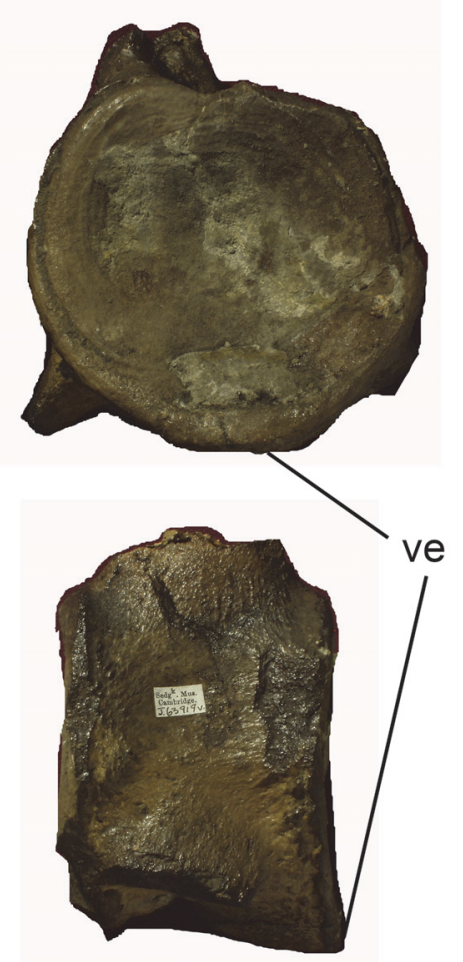

3

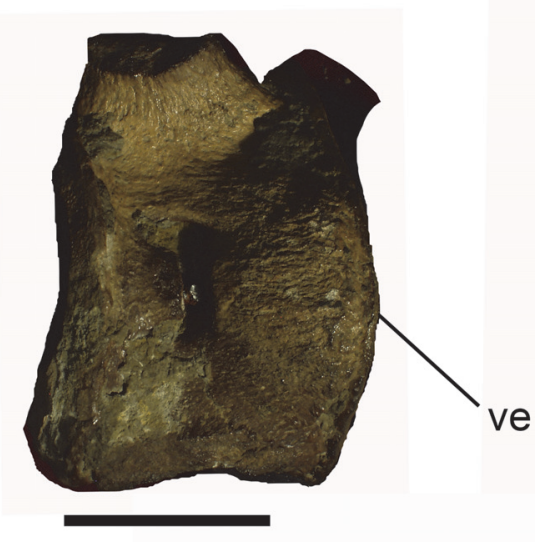

\section{5}

CV

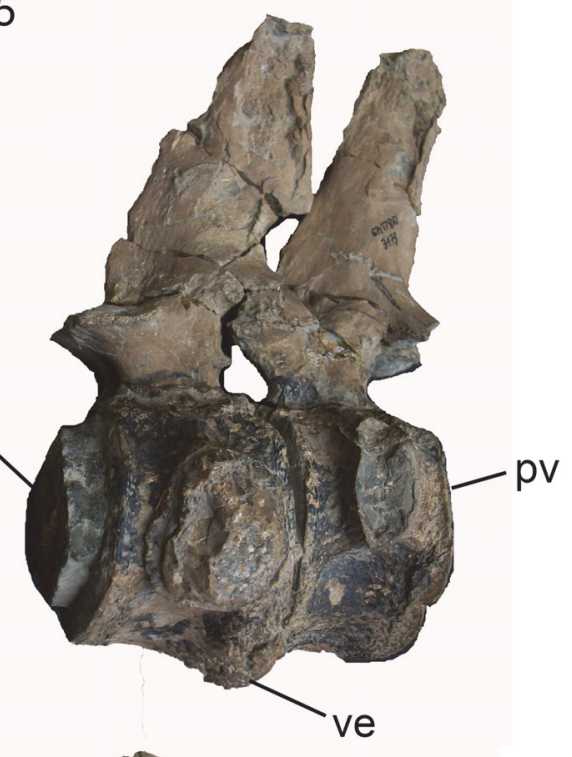

6
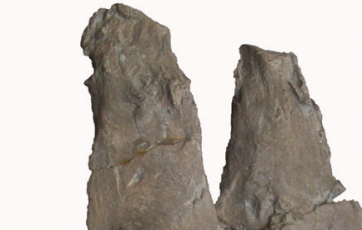

4

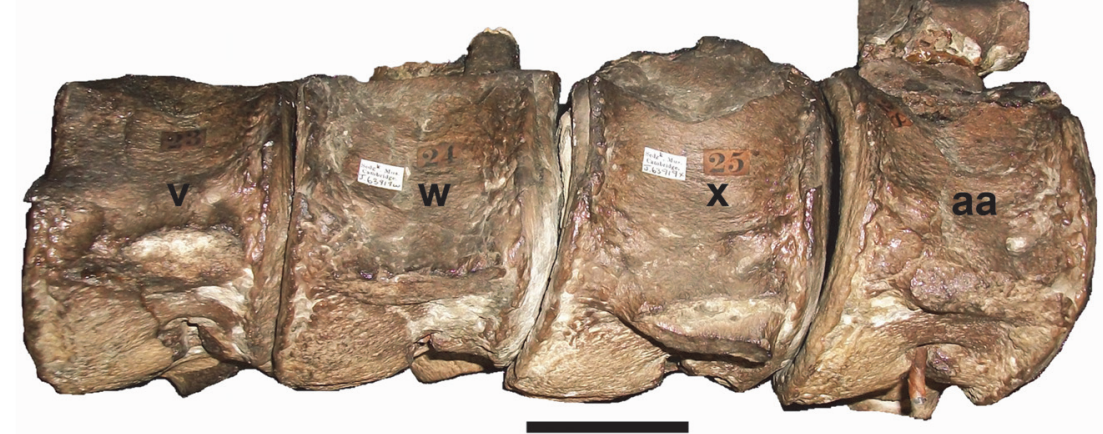

FIGURE 2. Pathological cervical vertebra from Colymbosaurus megadeirus (CAMSM J63919) in 1. anterior view 2. right lateral view 3. ventral view. 4. Left lateral view of pathological vertebrae in series, museum numbers CAMSM J63919 v, w, X, aa; estimated positions in cervical series 26 to 29. 5. Plesiosauroid (indet) (GPIT.RE.03173) terminal cervical and first pectoral in left lateral view and 6 . right lateral view. Abbreviations: $\mathrm{cv}$, cervical vertebra; pv, first pectoral vertebra; ve, pathological ventral expansions. Scale bar equals $3 \mathrm{~cm}$. 
placed foramina subcentralia are clearly present on some vertebra. Transversally flattened doubleheaded cervical ribs are attached ventrolaterally on the anteroposterior midlength of each centrum. In the more anterior vertebrae the ribs taper and lack an anterior process. The neural spines are short, i.e., less than half the height of the centra, inclined posterodorsally and bear a posterior projection. The projection does not touch the spines of adjacent vertebrae, and there is no dorsoventral bending of neural spines (Kubo et al., 2012).

The spinal pathologies of UCMP 38349 are present on two series of four vertebrae, numbered 15-19 and 23-27 on the specimen. The centra in series 23-27 are fused only on the ventral surface at the intervertebral joint by small osteophytes (Figure 3 ). In the series 15-19, vertebrae are joined together by unusual expansions around the lateral margin of the intervertebral joint, appearing as smooth, thick, spur-like swellings. They are most pronounced on the left lateral side of the ventral surface, close to the cervical rib especially at the junctions between vertebrae 15-16 and 16-17 (Figure 4). The fusions are not due to ossification of intervertebral ligaments but rather arise from proliferation of the ventral bone surface and ossification around the annulus fibrosus. No infection holes or bone density changes are apparent, and the surfaces of all vertebra studied are free of tooth marks. The pathology is highly localized and appears only on the ventral surfaces of intervertebral zone. It is very similar to the pathology observed on Colymbosaurus CAMSM J63919. However, in CAMSM J63919, the projection arises from the posterior surface of the vertebrae, contacting the anterior surface of the vertebral element following. The anterior and posterior surfaces of the first and last vertebra in each pathological series are normal, and articulate normally with their neighbours. A normal series of cervical vertebrae from UCMP 38349 with clear separations between centra is shown for comparison (Figure 4.3).

\section{DISCUSSION}

There are several potential causes of pathologic vertebral fusions. They include malformations during fracture healing or infections (Rothschild and Martin, 2006; Butler et al., 1990). Fractures on articular surfaces may result in osseous fusions of the articulations following fibrocartilage callus production (Cisneros et al., 2010). Fusions can occur after compressive fractures of one or more vertebral bodies and visible fracture lines are indicators of this process. In contrast, infections can be rec- ognised by the presence of drainage pits and sinuses. However, the specimens presented here show no evidence of fracture lines, scars or pits for pus release, so trauma, injury or healing malformation can be excluded as causes of the fusions.

Spondyloarthropathies can also be characterised by vertebral fusions. They are a category of arthritic diseases occasionally presenting with both non-vertebral and vertebral symptoms (Rothschild and Martin, 2006). Arthritic vertebral ankylosis is characterised by inflammation and progressive synostosis of anterior and posterior ligaments, leading to fusion of the vertebral bodies. Intervertebral discs are usually not affected (Rothschild, 1997; Rothschild and Martin, 2006). In the specimens described here, ossifications of longitudinal ligaments are apparently not present so the fusions are probably not due to spondyloarthropathies.

There are broadly two different kinds of pathologies in the described specimens. The vertebral fusions in specimens UCMP 38349, CAMSM J.63919, GPIT.RE.03173 are characterised by ossification and ventral bone overgrowth over the annulus fibrosus. These specimens are discussed together below. The fusion in the juvenile Muraenosaurus sp. NMW 19.96.G17 stands alone. There is no hyperostotic reactive bone overgrowth visible in the fused vertebra. Also the anteroposterior length of the fused vertebra is longer than that of the vertebrae preceding or following it in the series, but it is shorter than the expected length of two individual unfused vertebra. Thus the fused block is likely to be due to a failed segmentation of two vertebral elements at the prenatal stage (Britz and Johnson, 2005). Such congenital spinal abnormalities are irrecoverable malfunctions in embryonic development and are sometimes called block vertebrae (Molnar, 2001). They occur when there is an improper separation of somites during somitogenesis, a key part of early embryonic segmentation. The formation of somite boundaries is precisely timed and takes place in a rostrocaudal direction (Dequéant and Pourquié, 2008). If the separation of somites is incomplete, it can result in the fusion of vertebral centra.

The displacement of the foramina subcentralia (Figure 1.5) is especially interesting within the context of a congenital, developmental disorder. It was recently suggested that the paired ventral foramina subcentralia are exit points for a pair of vascular canals joining the ventral foramina to a pair of dorsal foramina (though it should be noted that in elasmosaurids the normal occurrence of a single foramen subcentrale has been reported, see 


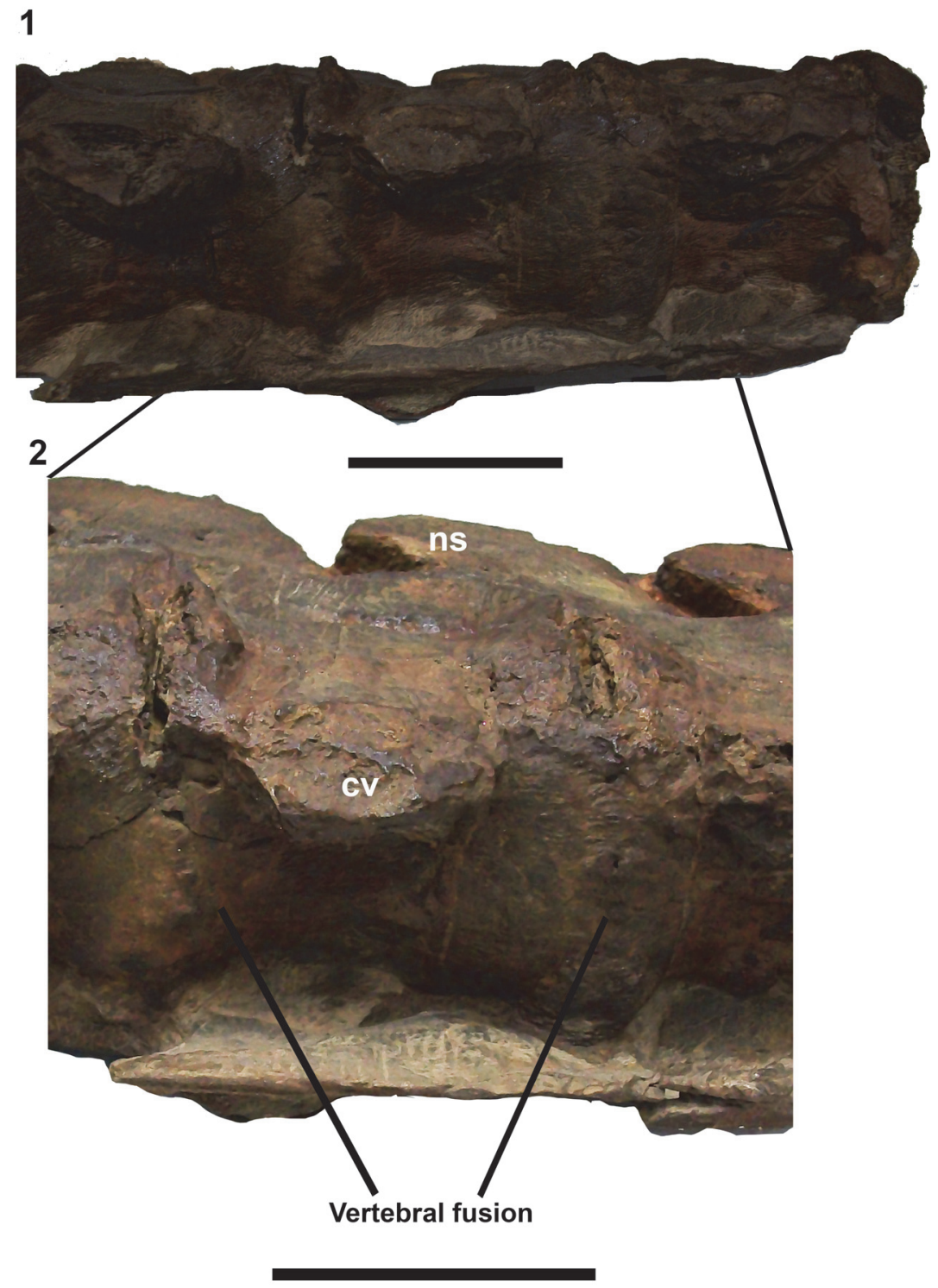

FIGURE 3. Cervical vertebral series from Callawayasaurus columbensis UCMP 38349 in ventral aspect. 1. Vertebrae $23,24,25$, anterior end, to right. Scale bar, $5 \mathrm{~cm}$. 2. Enlargement of osteophytic bridging between vertebrae 23-24, 2425. Abbreviations: ns, neural spine; cr, cervical rib. Scale bar equals $5 \mathrm{~cm}$.

Sachs and Kear, 2015, figure 4a). These canals cut through the middle of the centrum, passing through the centre of ossification (Wintrich et al., 2017). These vascular canals represent the embryonic intersegmental arteries that, uniquely in plesiosaurs, appear to persist into adulthood instead of being reabsorbed during sclerotome segmentation in early embryonic development, as in other vertebrates (Scaal, 2016). The fact that the foramina are displaced in NMW 19.96.G17 is in line with this hypothesis. It shows that the vessels running through the sclerotomes were already present when the sclerotomes re-segmented and were dis- placed by the improper separation of somites 12 and 13 , causing the fused block vertebrae.

Block vertebrae have been documented previously in the fossil record in Tyrannosaurus rex (Molnar, 2001), though this is the first description of the condition in a marine reptile. Evidence suggests that the basic development pattern of vertebra goes as far back as the most recent common ancestor of archosaurs and mammals. There are also a number of human syndromes associated with block vertebrae, such as Kippel-Feil Syndrome arising from the failure of normal segmentation of cervical somites (Turnpenny et al., 2007). 


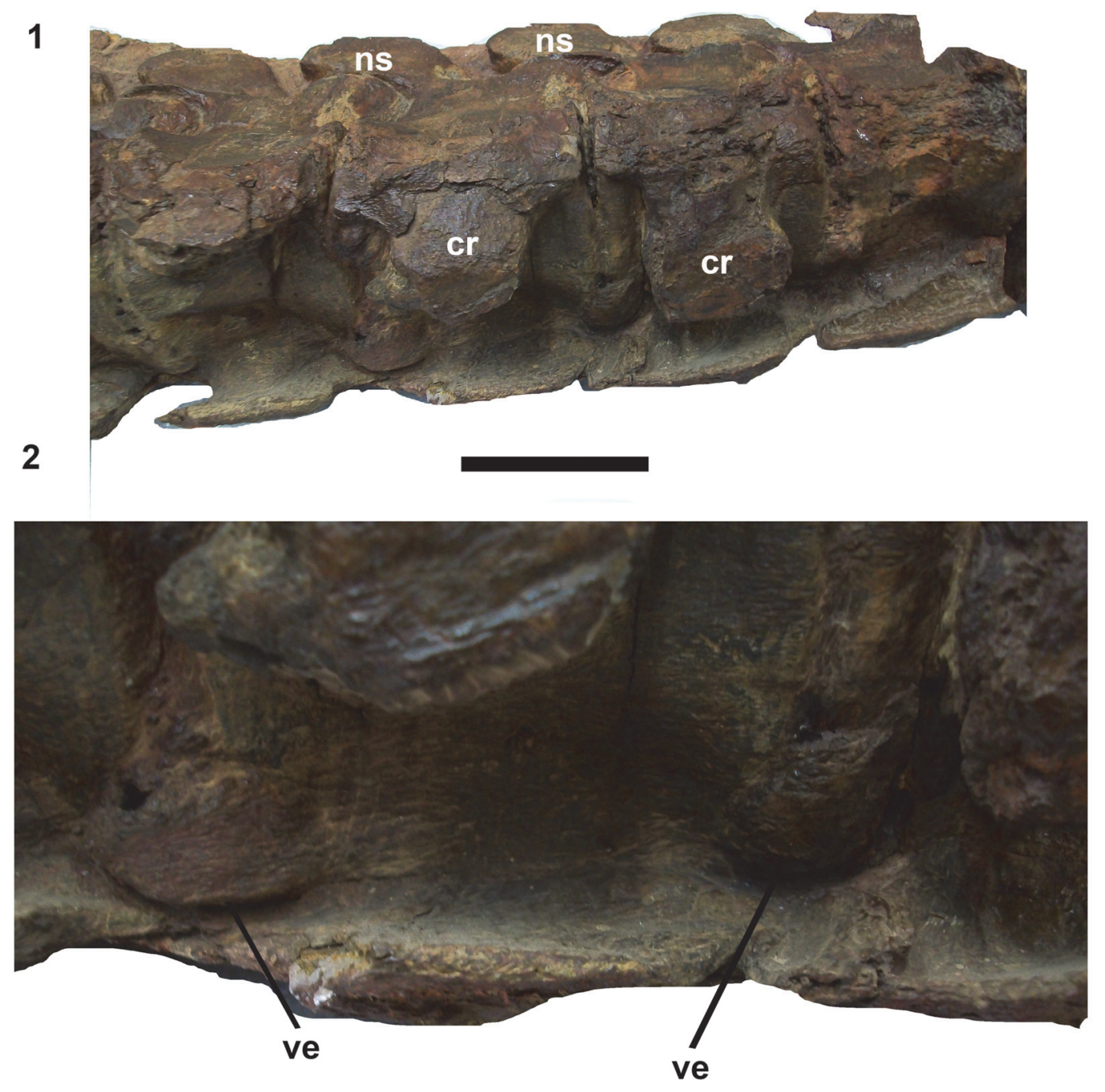

3

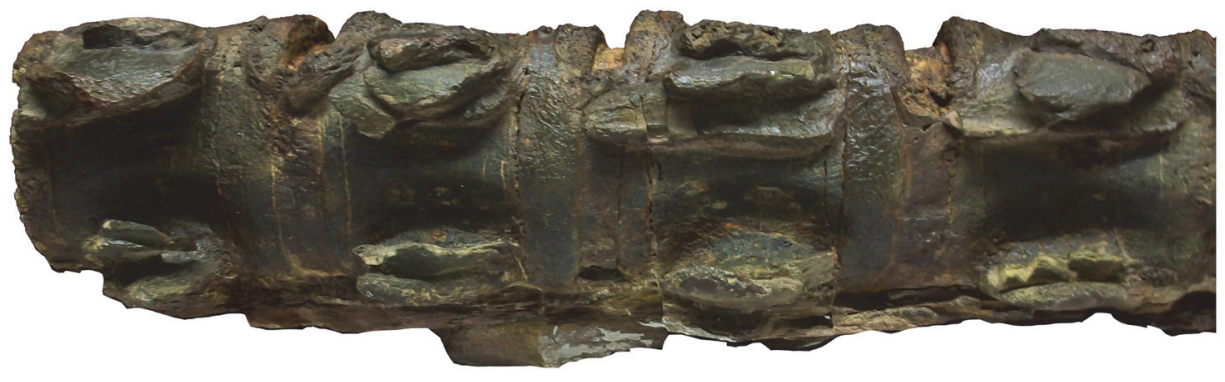

FIGURE 4. Cervical vertebral series from Callawayasaurus columbensis UCMP 38349 in ventral aspect. 1. Vertebrae 15-18, anterior end to right. Scale bar equals $5 \mathrm{~cm}$. 2. Enlargement showing claw-like ventral expansion projecting antero-posteriorly between vertebrae 16-17, 17-18. 3. Ventral view of cervical series from UCMP 38349 without pathologies, vertebrae 32-35. Abbreviations: ns, neural spine; cr, cervical rib; ve, pathological ventral expansion. Scale bar equals $5 \mathrm{~cm}$. 
Axial skeleton development is very sensitive to somitogenic perturbations, and in humans the conditions are sometimes congenital and sometimes sporadic (Cisneros et al., 2010). At the macroscopic level, mature centra are fused through their intervertebral discs and intervertebral joints, which can lead to the blocking or stretching of the exiting nerve roots from the segments and produce neurological problem or increase stress on intervertebral joints leading to an abnormal angle in the spine (Erdil et al., 2003). It is not possible to predict what effect the condition would have had on the longnecked Muraenosaurus. It may be significant that specimen NMW 19.96.G17 did not survive beyond the juvenile stage.

The pathologies in UCMP 38349, Callawayasaurus columbiensis, CAMSM J.63919 Colymbosaurus megadeirus and GPIT.RE.03173 (unknown plesiosauroid) may be grouped together on the basis of several similarities. In Callawayasaurus and Colymbosaurus they occur as a series of at least four fused vertebrae. Thick, claw-like expansions project ventrally and bridge adjacent vertebra together. The projections are located at the junction of the annulus fibrosus and the cortical surface of adjacent centra. In GPIT.RE.03173 only two vertebrae are preserved, fused by a similar ventral projection, and they may have been part of a longer series. In Callawayasaurus, which typically has 56 cervical vertebrae (Welles, 1962; Carpenter, 1999) there are two series of four fused centra, of anterior and middle vertebrae. The series are numbered 15-19 and 23-27, as preserved. In Colymbosaurus, with 41 cervical vertebrae, (Benson and Bowdler, 2014) the pathology is located in a middle cervical series, numbered 26-29. In the unclassified plesiosaur GPIT.RE.03173, the pathology is on the cervical-pectoral transition (Figure 2.5-6).

In all these specimens, the fusion arises from ossifications bridging consecutive centra on the ventral surface. The large bulbous spurs appear to arise from the vertebral ring apophyses. Comparison with known spinal disorders in veterinary literature suggests a tentative diagnosis of spondylosis deformans (or spondylosis). Spondylosis is a noninflammatory, degenerative condition involving the annulus fibrosus and displaying hyperostosis around the vertebral margins. The osteophytes vary from small spurs to bony bridges across the disc space and can protrude several millimeters from the disco-vertebral junction (Morgan et al., 1989; Langeland and Lingaas, 1995; Carnier et al., 2004; Levine et al., 2006). The position of the intervertebral disc height can also be affected by pro- gressive degeneration (Fardon and Milette, 2001; Gibson et al., 1999; Middleton and Fish, 2009; Binder, 2007; Shedid and Benzel, 2007; Muraki et al., 2009; Lee et al., 2011). Although sometimes referred to as osteophytes, some authors prefer the term enthesophytes for the bony projections in spondylosis deformans (Thomas and Fingeroth, 2014). This is because true osteophytes only occur at the osteochondral junction of synovial joints rather than junctions between vertebrae. The enthesophytes in the described plesiosaur specimens vary from small spurs to large bony swellings across the disc space, leaving at least some of the ventral surface of the centrum unaffected. The extent of the pathological ossification in veterinary medicine is graded according to the following system, usually on the basis of X-ray images (Figure 5) (Kranenberg et al., 2012):

Grade 0; no enthesophytes.

Grade 1; small enthesophyte at the edge of the epiphysis that does not extend past the end plate.

Grade 2; enthesophyte extends beyond the end plate but does not connect to enthesophyte on the adjacent vertebra.

Grade 3; enthesophytes on adjacent vertebrae connected to each other forming bony bridges between vertebrae.

The localised pathologies in UCMP 38349 and CAMSM J.63919 are at the most advanced stage, with grade 3 enthesophyte development (Figure 2.4; Figure 4.2; Figure 5).

The aetiology of spondylosis is not well known (Read and Smith, 1968; Langeland and Lingaas, 1995). It is proposed that abnormalities in the peripheral annular fibers lead to discontinuity and weakening of the anchorage of the intervertebral disc. This subsequently facilitates disc displacement (anterolateral or ventral in humans) causing traction at the site of the Sharpey fibers and development of osteophytes several millimeters from the disco-vertebral junction (Resnick, 1985).

The types of vertebral fusions presented here have not been described in the fossil literature. However, diffuse idiopathic skeletal hyperostosis (DISH), another disorder presenting with spinal hyperostosis, is known in museum specimens and should be mentioned because, although a separate disorder, it is sometimes associated with spondylosis deformans and is not always easy to distinguish from it (Kranenburg, 2013). DISH is an osteoarthritis of the central facet joints characterised by calcification and ossification of soft tissues such as the longitudinal spinal ligaments, sites of attachment of tendons or muscles and capsules to 


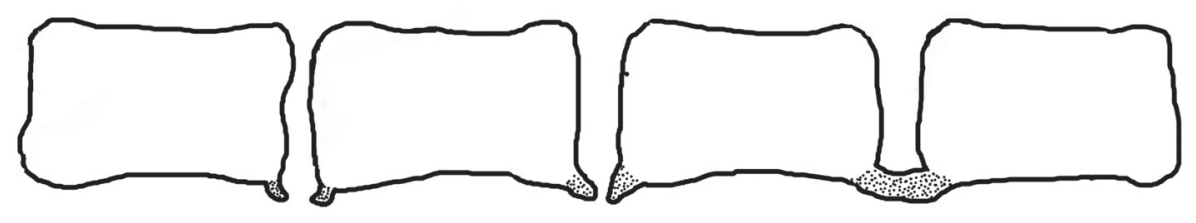

GRADE

0

1

2

3

2

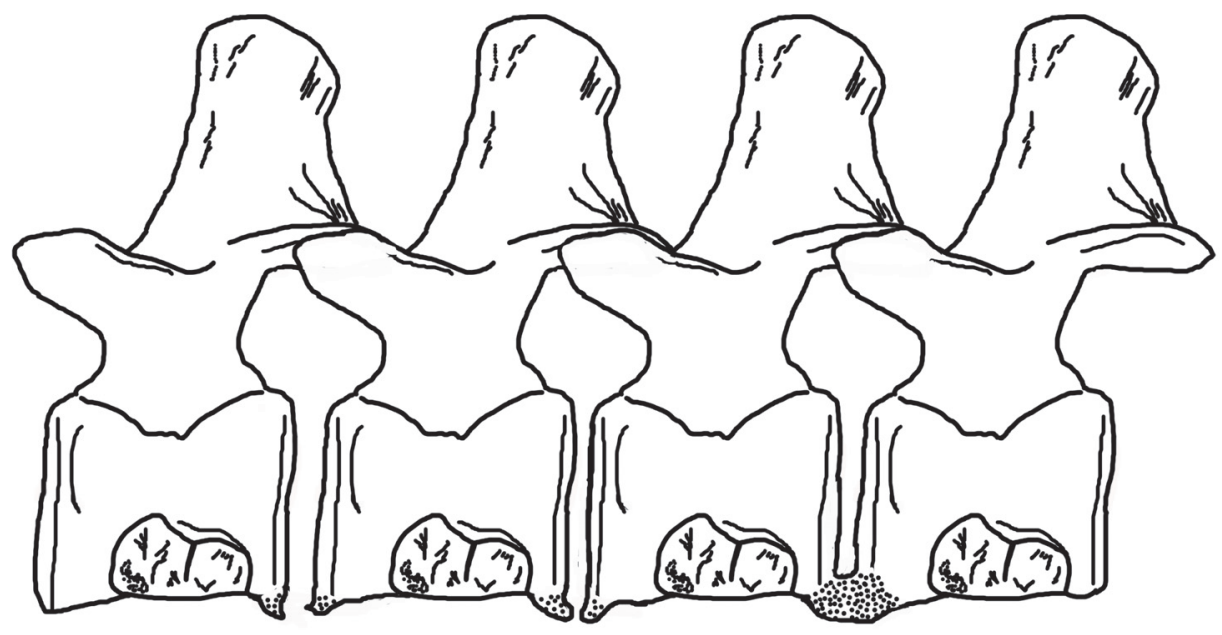

GRADE

3
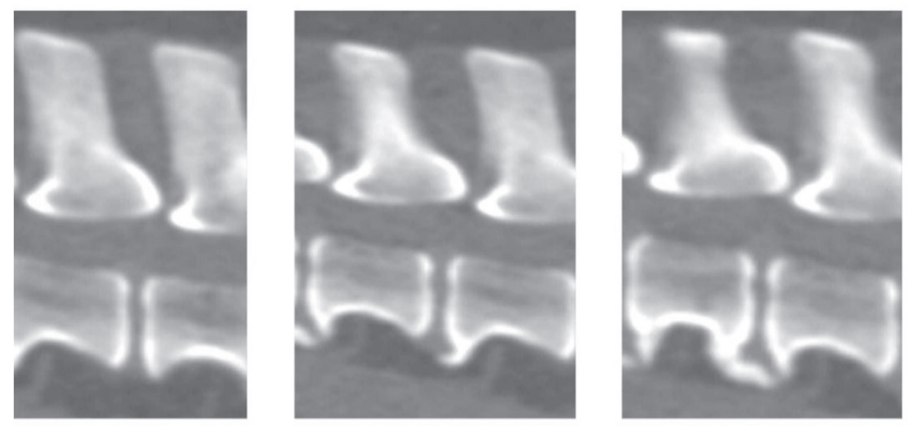

2

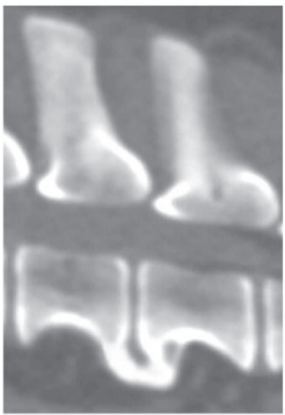

3

FIGURE 5. 1. General diagram of spondylosis deformans grades (based on Kranenberg et al., 2012) 2. Schematic diagram of plesiosaur cervical vertebrae showing spondylosis deformans grades. Grade 0: no enthesophytes. Grade 1: small enthesophyte at the edge of the epiphysis, not extending past the end plate. Grade 2: enthesophyte extending beyond the end plate but not connecting to enthesophyte on adjacent vertebra. Grade 3: enthesophytes on adjacent vertebrae connected forming bony bridges between vertebrae. 3. Reproduction of radiographic images of spondylosis deformans grades in a dog, for comparison. https://veteriankey.com/spondylosis-deformans/ 
bone (enthesis). DISH has been extensively described in both the archaeological (Bjorkengren et al., 1987; Rothschild, 1987; Chhem et al., 2004; Verlaan et al., 2007; Giuffra et al., 2010) and palaeontological literature, e.g., in dinosaurs, a Sabretoothed cat and old Rhesus monkeys (Sokoloff et al., 1968; Bjorkengren et al., 1987 Rothschild, 1987). In modern humans DISH is a common, systemic disorder of the axial and peripheral skeleton in the middle-aged and elderly, and there are also reports of DISH in companion animals, especially dogs (Woodard et al., 1985; Morgan and Stavenborn, 1991; Kranenburg et al., 2013).

The distinction between spondylosis and $\mathrm{DISH}$ in human medicine is clearer than in veterinary medicine. In humans, spondylosis describes a degenerative disc disease combined with enthesophytes (Gibson et al., 1999; Binder, 2007; Harrop et al., 2007; Shedid and Benzel, 2007; Middleton and Fish, 2009; Muraki et al., 2009; Lee et al., 2011). In advanced DISH, the intervertebral discs are generally not degenerated, so a diagnosis can be made on the basis of X-rays (Kranenburg et al., 2013). However, in the veterinary literature, spondylosis is used to describe spinal osteophytes without necessarily showing signs of intervertebral disc degeneration. Thus the distinction between spondylosis and especially early stage DISH is more difficult and occasionally the two conditions have been described together, for example in dogs (Kranenburg et al., 2013).

The enthesophyte spurs on the plesiosaur specimens differ from the ossifications and longitudinal ligament hyperostosis characteristic of DISH (Kranenberg et al., 2010; 2012; 2013). In DISH, the new bone formation is more flowing and often presents as a "dripping candle wax" calcification effect, which is not seen in any of the specimens (Figures $2,3,4)$. However, DISH always affects several vertebrae in a series, usually four or more contiguous vertebrae (Haller et al., 1989) and in at least two of the plesiosaur specimens, there are four contiguous vertebrae showing pathological fusion. Nevertheless, it is unlikely that DISH is the cause of these pathologies because the vertebrae do not show signs of fibroligament calcification but rather more localised ossifications of the annulus fibrosus suggestive of a disc abnormality. Thus spondylosis deformans is the more likely condition observed here.

The pathologies presented here show that Mesozoic marine reptiles from a range of horizons suffered from spinal diseases similar to those affecting modern vertebrates. The pathologies may have caused dysmorphosis of the neck but, given the minimal extent of fusions, the in-life visibility of the pathologies would have been limited. Also, Callawayasaurus and Colymbosaurus specimens were mature adults (sensu Brown, 1981) a conclusion based on the complete fusion of neural spines to the centra, so the vertebral ossification was clearly not immediately life threatening. There have even been suggestions in the literature that vertebral fusions might occasionally create an evolutionary advantage for at least some large bodied animals (Rothschild and Martin, 2006). For example, sauropod dinosaurs such as Apatosaurus, Camarasaurus, and Diplodocus often had fused adjacent caudal vertebrae (Rothschild and Berman, 1991). It was suggested that localised caudal fusions might have created a cantilever effect that benefited sauropods by providing extra body support from the tail for males during mating (Rothschild and Berman, 1991). In ceratopsians, the first three cervical vertebrae are fused into a structure known as the syncervical, which may have added support to the animals' massive skulls (Rothschild, 1997). Though the potential functional benefits of intervertebral fusion in plesiosaurs remains uncertain, it is clear that they would have increased the rigidity of the vertebral column and this might have created an advantage especially for very longnecked plesiosaurs. Noè et al. (2017) advanced a new model of the plesiosaur body plan, laying great emphasis on the importance of a stiff neck. They modelled the plesiosaur head as a filtering, sieving or sediment raking apparatus mounted on a stiff neck with limited ventral flexibility. O'Keefe et al. (2017) made a similar proposal for the feeding mode of the aristonectine elasmosaur, Morturneria seymourensis. The neck thus acted as a feeding tube, and the head and neck were held steady whilst swimming. Most of the movement and agility of the plesiosaur came from the body (thorax, abdomen, limbs) acting as a mobile feeding platform. If this model is correct, intervertebral fusions might have been either beneficial or, at least, not detrimental to the plesiosaurs' feeding and survival.

\section{ACKNOWLEDGMENTS}

The author would like to thank M. Riley (Sedgwick Museum, Cambridge UK), C. Howells (National Museum of Wales, Cardiff), P. Holroyd (University of California Museum of Paleontology, 
Berkeley, California, USA), P. Havlik (GeologischPaläontologisches Institut Tübingen, Tübingen, Germany) for granting access to museum collec- tions. Thanks also to M. Benton, R. Forrest and S. Sachs for their helpful comments on the manuscript.

\section{REFERENCES}

Barrett, L. 1858. On the atlas and axis of the Plesiosaurus. Annals and Magazine of Natural History, third series, 2:361-364.

Benson, R.B.J. and Druckenmiller, P.S. 2014. Faunal turnover of marine tetrapods during the Jurassic-Cretaceous transition. Biological Reviews of the Cambridge Philosophical Society, 89:1-23. https://doi.org/10.1111/brv.12038

Benson, R.B.J. and Bowdler, T. 2014. Anatomy of Colymbosaurus megadeirus (Reptilia, Plesiosauria) from the Kimmeridge Clay Formation of the U.K. and high diversity among Late Jurassic plesiosauroids. Journal of Vertebrate Paleontology, 34:1053-1071. https://doi.org/ $10.1080 / 02724634.2014 .850087$

Binder, A.I. 2007. Cervical spondylosis and neck pain. British Medical Journal, 334:527-531. https://doi.org/10.1136/bmj.39127.608299.80

Blumberg, B.S. and Sokoloff, L. 1961. Coalescence of caudal vertebrae in the giant dinosaur Diplodocus. Arthritis and Rheumatism, 4:592-601. https://doi.org/10.1002/art.1780040605

Britz, R. and Johnson, G.D. 2005. Occipito-vertebral fusion in ocean sunfishes (Teleostei: Tetraodontiformes: Molidae) and its phylogenetic implications. Journal of Morphology, 266:74-79. https://doi.org/10.1002/jmor.10366

Brown, D.S. 1981. The English Upper Jurassic Plesiosauridea (Reptilia) and a review of the phylogeny and classification of the Plesiosauria. Bulletin of the British Museum of Natural History, 35:253-347.

Bjorkengren, A.G., Sartoris, D.J., Shermis S., and Resnick, D. 1987. Patterns of paravertebral ossification in the prehistoric saber-toothed cat. American Journal of Roentgenology, 148:779-782. https://doi.org/10.2214/ajr.148.4.779

Butler, D., Trafimow, J.H., Andersson, B.J., McNeill, T.W., and Huckman, M.S. 1990. Discs degenerate before facets. Spine, 15:111-113. https://doi.org/10.1097/00007632-19900200000012

Butler, R.J., Yates, A.M., Rauhut, O.W.M., and Foth, C. 2013. A pathological tail in a basal sauropodomorph dinosaur from South Africa: evidence of traumatic amputation? Journal of Vertebrate Paleontology, 33:224-228. https://doi.org/10.1080/02724634.2012.710691

Carnier, P., Gallo, L., Sturaro, E., Piccinini, P., and Bittante, G. 2004. Prevalence of spondylosis deformans and estimates of genetic parameters for the degree of osteophytes development in Italian Boxer dogs. Journal of Animal Science, 82:85-92. https://doi.org/10.1080/ 02724634.2012.710691

Carpenter, K. 1999. Revision of North American elasmosaurs from the Cretaceous of the Western Interior. Paludicola, 2:148-173.

Chhem, R.K., Schmit, P., and Faure, C. 2004. Did Ramesses II really have ankylosing spondylitis? A reappraisal. Canadian Association of Radiologists Journal, 55:211-217.

Chi, J.H., Tay, B., Stahl, D., and Lee, R. 2007. Complex deformities of the cervical spine. Neurosurgery Clinics of North America, 18:295-304. https://doi.org/10.1016/ j.nec.2007.01.003

Cisneros, J.C., Cabral, U.G., de Beer, F., Damiani, R., and Fortier, D.C. 2010. Spondarthritis in the Triassic. PLOS ONE, 5: e13425. https://doi.org/10.1371/journal.pone.0013425

Cope, E.D. 1869. Synopsis of the extinct Batrachia Reptilia, and Aves of North America. Transactions of the American Philosophical Society, New Series, 14:1-104.

De Blainville, H. 1835. Description de quelques espèces de reptiles, de la Californie, precede de l'analyse d'un système general d'Erpetologie at d'Amphibiologie. Nouvelles Annales de Museum National d'Histoire Naturelle, Paris, 4:233-296.

Dequéant, M-L. and Pourquié, O. 2008 Segmental patterning of the vertebrate embryonic axis. Nature Reviews Genetics, 9:370-382. https://doi.org/10.1038/nrg2320 
Erdil, H., Yildiz, N., and Cimen, M. 2003. Congenital fusion of cervical vertebrae and its clinical significance. Journal of the Anatomical Society of India, 52:125-127.

Fardon, D.F. and Milette, P.C. 2001. Nomenclature and classification of lumbar disc pathology. Recommendations of the combined task forces of the North American Spine Society, American Society of Spine Radiology, and American Society of Neuroradiology. Spine, 26:E93-E113. https://doi.org/10.1097/00007632-200103010-00006

Farke, A.A. and O'Connor, P.M. 2007. Pathology in Majungasaurus crenatissimus (Theropoda: Abelisauridae) from the Late Cretaceous of Madagascar. Journal of Vertebrate Paleontology, 27:180-184. https://doi.org/10.1671/0272-4634(2007)27[180:pimcta]2.0.co;2

Gibson, J.N., Grant, I.C., and Waddell, G. 1999. The cochrane review of surgery for lumbar disc prolapse and degenerative lumbar spondylosis. Spine, 24:1820-1832. https://doi.org/ 10.1097/00007632-199909010-00012

Giuffra, V., Giusiani, S., Fornaciari, A., Villari, N., Vitiello, A., and Fornaciari, G. 2010. Diffuse idiopathic skeletal hyperostosis in the Medici, Grand Duke of Florence (XVI century). European Spine Journal, Supplement 2, 19:S103-S107. https://doi.org/10.1007/s00586-0091125-3

Goñi, R. and Gasparini, Z. 1983. Nuevos restos de "Alzadasaurus colombiensis" (Reptilia, Plesiosauria) del Cretácico temprano de Colombia. Geología Norandina, 7:49-54.

Gray, J.E. 1825. A synopsis of the genera of reptiles and amphibia, with a description of some new species. Annals of Philosophy, 26:193-217.

Haller, J., Resnick, D., Miller, C.W., Schils, J.P., Kerr, R., Bielecki, D., Sartoris, D.J., and Gundry, C.R. 1989. Diffuse idiopathic skeletal hyperostosis: diagnostic significance of radiographic abnormalities of the pelvis. Radiology, 172:835-839. https://doi.org/10.1148/ radiology.172.3.2788894

Harrop, J.S., Hanna, A., Silva, M.T., and Sharan, A. 2007. Neurological manifestations of cervical spondylosis: an overview of signs, symptoms, and pathophysiology. Neurosurgery, 60:S14-S20. https://doi.org/10.1227/01.neu.0000215380.71097.ec

Kear, B.P. 2007. A juvenile pliosauroid plesiosaur (Reptilia: Sauropterygia) from the Lower Cretaceous of South Australia. Journal of Paleontology, 8:154-162. https://doi.org/10.1666/ 0022-3360(2007)81[154:ajpprs]2.0.co;2

Ketchum, H.F. and Benson, R.B.J.2010. Global interrelationships of Plesiosauria (Reptilia,Sauropterygia) and the pivotal role of taxon sampling in determining the outcome of phylogenetic analyses. Biological Reviews, 85:361-392. https://doi.org/10.1111/j.1469185X.2009.00107.x

Kranenburg, H.C., Westerveld, L.A., Verlaan, J.J., Oner F.C., Dhert W.J.A., Voorhout G., Hazewinkel H.A.W., and Mei, B.P. 2010. The dog as an animal model for DISH? European Spine Journal, 19:1325-1329. https://doi.org/10.1007/s00586-010-1280-6

Kranenburg, H.C., Meij, B.P., van Hofwegen, E.M.L., Voorhout, G., Slingerland, L.I., Picavet, P., and Hazewinkel, H.A.W. 2012. Prevalence of spondylosis deformans in the feline spine and correlation with owner-perceived behavioural changes. Veterinary and Comparative Orthopaedics and Traumatology, 25:217-223. https://doi.org/10.3415/vcot-11-06-0092

Kranenburg , H.A., Hazewinkel, H.A.W., and Meij, B.P. 2013. Spinal hyperostosis in humans and companion animals. Veterinary Quarterly, 33:30-42. https://doi.org/10.1080/ 01652176.2013 .770181

Kubo, T., Mark, T., Mitchell, M.T., and Henderson, D.M. 2012. Albertonectes vanderveldei, a new elasmosaur (Reptilia, Sauropterygia) from the Upper Cretaceous of Alberta. Journal of Vertebrate Paleontology, 32:557-572. https://doi.org/10.1080/02724634.2012.658124

Langeland, M. and Lingaas, F. 1995. Spondylosis deformans in the boxer: estimates of heritability. Journal of Small Animal Practice, 36:166-169. https://doi.org/10.1111/j.17485827.1995.tb02872.x

Lee, J.Y., Hohl, J.B., Fedorka, C.J., Devin, C., Brodke, D.S., Branch, C.L., Jr., and Vaccaro, A.R. 2011. Surgeons agree to disagree on surgical options for degenerative conditions of the cervical and lumbar spine. Spine, 36:E203-E212. https://doi.org/10.1097/ brs.0b013e3181df8063

Levine, G.J., Levine, J.M., Walker, M.A., Pool, R.R., and Fosgate, G.T. 2006. Evaluation of the association between spondylosis deformans and clinical signs of intervertebral disk disease in dogs: 172 cases (1999-2000). Journal of the American Veterinary Medical Association, 228:96-100. https://doi.org/10.2460/javma.228.1.96 
Littleton, J. 1999. Paleopathology of skeletal fluorosis. American Journal of Physical Anthropology, 109:465-483. https://doi.org/10.1002/(SICl)10968644(199908)109:4<465::AID-AJPA4>3.0.CO;2-T

Martin, J.E. and Bell, G.L. 1995. Abnormal caudal vertebrae of Mosasauridae from Late Cretaceous marine deposits of South Dakota. Proceedings of the South Dakota Academy of Science, 74:23-27.

Middleton, K. and Fish, D.E. 2009. Lumbar spondylosis: clinical presentation and treatment approaches. Current Reviews in Musculoskeletal Medicine, 2:94-104. https://doi.org/ 10.1007/s12178-009-9051-x

Molnar, R.E. 2001. Theropod paleopathology: a literature survey, p. 337-363. In Tanke, D.H. and Carpenter, K. (eds.), Mesozoic Vertebrate Life. Indiana University Press, Bloomington.

Morgan, J.P. and Stavenborn, M. 1991. Disseminated idiopathic skeletal hyperostosis (DISH) in a dog. Veterinary Radiology and Ultrasound, 32:65-70. https://doi.org/10.1111/j.17408261.1991.tb00082.x

Morgan, J.P., Hansson, K., and Miyabayashi, T. 1989. Spondylosis deformans in the female beagle dog: A radiographic study. Journal of Small Animal Practice, 30:457-460. https:// doi.org/10.1111/j.1748-5827.1989.tb01607.x

Mudge, B.F. 1878. Geology of Kansas. Biennial Report of the Kansas State Board of Agriculture, 1:60-63.

Mulder, E.W.A. 2001. Co-ossified vertebrae of mosasaurs and cetaceans: implications for the mode of locomotion of extinct marine reptiles. Paleobiology, 27:724-734. https://doi.org/ 10.1666/0094-8373(2001)027<0724:COVOMA>2.0.CO;2

Muraki, S., Oka, H., Akune, T., Mabuchi, A., En-Yo, Y., Yoshida, M., Saika, A., Suzuki, T., Yoshida, H., Ishibashi, H., Yamamoto, S., Nakamura, K., Kawaguchi, H., and Yoshimura, N. 2009. Prevalence of radiographic lumbar spondylosis and its association with low back pain in elderly subjects of population-based cohorts: The ROAD study. Annals of Rheumatic Diseases, 68:1401-1406. https://doi.org/10.1016/j.joca.2009.04.005

Noè, L.F., Taylor, M.A., and Gomez-Perez M. 2017. An integrated approach to understanding the role of the long neck in plesiosaurs. Acta Palaeontologica Polonica, 62:137-162. https:// doi.org/10.4202/app.00334.2016

O'Keefe, F.R. 2002. The evolution of plesiosaur and pliosaur morphotypes in the Plesiosauria (Reptilia: Sauropterygia). Paleobiology, 28:101-112. https://doi.org/10.1666/00948373(2002)028<0101:teopap>2.0.co;2

O'Keefe F.R and Hiller, N. 2006. Morphologic and ontogenetic patterns in Elasmosaur neck length, with comments on the taxonomic utility of neck length variables. Paludicola, 5:206229.

O'Keefe, F. R., Otero, R.A., Soto-Acuña, S., O'Gorman, J.P., Godfrey, S.J., and Chatterjee, S. 2017. Cranial anatomy of Morturneria seymourensis from Antarctica, and the evolution of filter feeding in plesiosaurs of the Austral Late Cretaceous. Journal of Vertebrate Paleontology, 37:e1347570. https://doi.org/10.1080/02724634.2017.1347570

Owen, R. 1860. On the orders of fossil and recent Reptilia, and their distribution through time. Report of the British Association for the Advancement of Science, 1859:153-166.

Read, R.M. and Smith, R.N. 1968. A comparison of spondylosis deformans in the English and Swedish cat and in the English dog. Journal of Small Animal Practice. 9:159-166. https:// doi.org/10.1111/j.1748-5827.1968.tb04605.x

Resnick, D. 1985. Degenerative diseases of the vertebral column. Radiology, 156:3-14. https:// doi.org/10.1148/radiology.156.1.3923556

Rogers, J., Watt, I., and Dieppe, P. 1985. Palaeopathology of spinal osteophytosis, vertebral ankylosis, ankylosing spondylitis, and vertebral hyperostosis. Annals of the Rheumatic Diseases, 44:113-120. https://doi.org/10.1136/ard.44.2.113

Rothschild, B.M. 1987. Diffuse idiopathic skeletal hyperostosis as reflected in the paleontologic record: dinosaurs and early mammals. Seminars in Arthritis and Rheumatism. 17:119-125. https://doi.org/10.1016/0049-0172(87)90034-5

Rothschild, B.M. 1997. Dinosaurian paleopathology, p. 426-448. In Farlow, J.O. and BrettSurman, M.K. (eds.), The Complete Dinosaur. Indiana University Press, Bloomington

Rothschild, B.M. 2013. Diffuse idiopathic skeletal hyperostosis. eMedecine Orthopedic Surgery. http://emedicine.medscape.com/article/1258514-overview 
Rothschild, B.M. and Berman, D.S. 1991. Fusion of caudal vertebrae in late Jurassic sauropods. Journal of Vertebrate Paleontology, 11:29-36. https://doi.org/10.1080/ 02724634.1991 .10011373

Rothschild, B.M. and Everhart, M.J. 2012. Co-ossification of vertebrae in mosasaurs (Squamata, Mosasauridae): Evidence of habitat interactions and susceptibility to bone disease. Transactions of the Kansas Academy of Sciences, 118:265-275.

Rothschild, B.M. and Martin, L.D. 2006. Skeletal impact of disease. New Mexico Museum of Natural History and Science Bulletin, 33:1-226.

Rothschild, B.M., Helbing, M., and Miles, C. 2002. Spondyloarthropathy in the Jurassic. The Lancet, 360:1454. https://doi.org/10.1016/s0140-6736(02)11471-1

Rothschild, B.M., Schultze, H-P., and Pellegrini, R. 2012. Herpetological Osteopathology: Annotated Bibliography of Amphibians and Reptiles. Springer, New York.

Sachs, S., Hornung, J.J. and Kear, B.P.R. 2016. Reappraisal of Europe's most complete Early Cretaceous plesiosaurian: Brancasaurus brancai Wegner, 1914 from the "Wealden facies" of Germany. PeerJ, 22:e2813. https:///doi.org/10.7717/peerj.2813

Sachs, S. and Kear, B. 2015. Postcranium of the paradigm elasmosaurid plesiosaurian Libonectes morgani (Welles, 1949). Geological Magazine, 152:694-710. https://doi.org/ $10.1017 /$ S0016756814000636

Scaal, M. 2016. Early development of the vertebral column. Seminars in Cell and Developmental Biology, 49:83-91. https://doi.org/10.1016/j.semcdb.2015.11.003

Seeley, H.G. 1869. Index to the Fossil Remains of Aves, Ornithosauria, and Reptilia, in the Woodwardian Museum of the University of Cambridge. Deighton, Bell and Co., Cambridge, U.K.

Seeley, H.G. 1874. On Murænosaurus leedsii, a Plesiosaurian from the Oxford Clay. Quarterly Journal of the Geological Society, Part 1, 30:197-208

Shedid, D. and Benzel, E.C. 2007. Cervical spondylosis anatomy: pathophysiology and biomechanics. Neurosurgery, 60:S7-S13. https://doi.org/10.1227/ 01.neu.0000215430.86569.c4

Sokoloff, L., Snell, K.C., and Stewart, H.L. 1968. Spinal ankylosis in old rhesus monkeys. Clinical Orthopaeodics and Related Research, 61:285-293. https://doi.org/10.1097/00003086196811000-00032

Thomas, W.B. and Fingeroth, J.M. 2014. Spondylosis deformans, p. 67-74. In Fingeroth, J.M. and Thomas. W.B. (eds.), Advances in Intervertebral Disc Disease in Dogs and Cats. John Wiley \& Sons. https://doi.org/10.1002/9781118940372.ch8

Turnpenny, P.D., Alman, B., Cornier, A.S,, Giampietro, P.F., Offiah, A., Tassy, O., Pourquie, O., Kusumi, K., and Dunwoodie, S. 2007. Abnormal vertebral segmentation and the notch signaling pathway in Man. Developmental Dynamics, 236:1456-1474. https://doi.org/ 10.1002/dvdy.21182

Verlaan, J.J., Oner, F.C., and Maat, G.J. 2007. Diffuse idiopathic skeletal hyperostosis in ancient clergymen. European Spine Journal, 16:1129-1135. https://doi.org/10.1007/s00586-0070342-x

Welles, S. 1962. A new species of elasmosaur from the Aptian of Colombia and the review of the Cretaceous plesiosaurs. University of California Publications in Geological Sciences, 44:196.

Williston, S.W. 1925. Osteology of the Reptilia. University of Chicago Press, Chicago.

Wintrich, T., Scaal, M., and Sander, M. 2017. Foramina in plesiosaur cervical centra indicate a specialised vascular system. Fossil Record, 20:279-290. https://doi.org/10.5194/fr-20-2792017

Woodard, J.C., Poulos, P.W., Jr., Parker, R.B., Jackson, R.I., Jr., and Eurell, J.C. 1985. Canine diffuse idiopathic skeletal hyperostosis. Veterinary Pathology, 22:317-326. https://doi.org/ 10.1177/030098588502200404

Wu, H.T., Chou, C.T., Chiou, H.J., and Chang, C.Y. 2008. Imaging characteristics of spondyloarthropathy. Current Rheumatology Reviews, 4:124-130. https://doi.org/10.2174/ 157339708784310338 